\title{
PENERAPAN QR CODE SEBAGAI MEDIA ABSENSI YANG DIDUKUNG WHATSAPP SEBAGAI NOTIFIKASI PEMBAYARAN PADA SIAKAD
}

\author{
Moh. Denny Setiawan ${ }^{1}$, Resty Wulanningrum ${ }^{2}$, Daniel Swanjaya ${ }^{3}$ \\ Program Studi Teknik Informatika, Fakultas Teknik, Nusantara PGRI Kediri \\ Jl. K. H. Achmad Dahlan No.76 \\ (0354)772576, 771603 Kediri \\ E-mail:moh.dennysetiawan0115@gmail.com ${ }^{1}$,resty0601@gmail.com ${ }^{2}$,daniel@unpkediri.ac.id ${ }^{3}$
}

\begin{abstract}
ABSTRAKS
Penelitian ini bertujuan untuk menghasilkan sistem absensi dengan memanfaatkan $Q R$ code yang didukung pesan whatsapp sebagai notifikasi pembayaran yang terhubung dengan sistem informasi akademik. Notifikasi berupa pesan whatsapp akan muncul jika siswa belum melunasi jumlah pembayaran yang harus dipenuhi. Selain itu QR Code yang digunakan untuk absen juga dapat digunakan untuk login pada sistem informasi akademik. Dalam proses login menggunakan QR Code, sistem akan merekam username dan password. Sedangkan dalam proses absensi, sistem akan merekam nis, nama siswa, kelas dan waktu kehadiran. Metode pengembangan yang digunakan adalah metode SDLC model waterfall. Bahasa pemrograman yang digunakan adalah PHP dengan database MySQL yang dirancang dalam bentuk aplikasi berbasis website. Pengiriman notifikasi pesan whatsapp menggunakan API whatsapp wablas. Hasil dari penelitian ini adalah sebuah sistem informasi akademik yang memanfaatkan QR Code sebagai media absensi dan didukung pesan whatsapp sebagai notifikasi pembayaran.
\end{abstract}

Kata Kunci: Absensi, QR Code, Pembayaran, Whatsapp.

\begin{abstract}
This study aims to produce an attendance system by utilizing a QR code that is supported by WhatsApp messages as payment notifications that are connected to the academic information system. A notification in the form of a whatsapp message will appear if the student has not paid the amount of payment that must be fulfilled. In addition, the QR Code used for absenteeism can also be used to login to the academic information system. In the login process using the QR Code, the system will record the username and password. While in the attendance process, the system will record the name, name of the student, class and time of attendance. The development method used is the waterfall model SDLC method. The programming language used is PHP with a MySQL database designed in the form of a website-based application. Sending whatsapp message notifications using the wablas whatsapp API. The result of this study is an academic information system that uses QR Code as attendance media and is supported by WhatsApp messages as payment notifications.
\end{abstract}

Keywords: Attendance, QR Code, Payment, Whatsapp.

\section{PENDAHULUAN}

\subsection{Latar Belakang}

Pada perkembangan teknologi yang semakin maju dan pesat saat ini akan tentu berpengaruh pada kemudahan-kemudahan yang diberikan dalam kehidupan sehari-hari terutama dalam bidang pemerintahan, perusahaan dan pendidikan (Sholeh, 2016). Dalam kegiatan belajar mengajar di suatu lembaga pendidikan, tentu saja memiliki seseorang yang harus di catat kehadirannya setiap hari. Pencatatan kehadiran ini lebih sering dikenal sebagai presensi. Presensi atau yang biasa dikenal dengan sebutan absensi adalah suatu kegiatan atau rutinitas yang dilakukan oleh seseorang untuk membuktikan kehadirannya dalam suatu pertemuan (lengkong, 2016). Absensi dapat dikatakan suatu pendataan kehadiran yang merupakan bagian dari aktifitas pelaporan yang ada dalam sebuah instansi. Absensi disusun dan diatur sehingga mudah untuk dicari dan dipergunakan ketika diperlukan oleh pihak yang berkepentingan (Setiawan, 2015).

Absensi merupakan salah satu poin yang memegang peranan penting dalam setiap pertemuan, terutama pertemuan yang bersifat formal. Absensi dalam sebuah pertemuan menjadi objek pertimbangan dalam menentukan sebuah output, pertemuan di lingkungan pendidikan misalnya. Dalam kegiatan belajar mengajar sekarang ini, masih banyak lingkungan pendidikan yang menerapkan sistem absensi dalam bentuk manual, seperti mengisi absensi dengan menandatangani daftar absen yang tersedia, ataupun dengan memanggil satu persatu nama-nama yang terdapat dalam lembar absensi. Sehingga kegiatan absen secara manual dirasa kurang efektif jika diterapkan di dalam suatu pertemuan dengan kapasitas siswa yang cukup 
banyak dalam satu kelas dengan alasan lost time serta terjadinya pemborosan kertas absensi. Ditemukan pula adanya potensi kecurangan yang dilakukan oleh siswa dengan mewakilkan tanda tangan siswa lain yang tidak hadir (Irawan, 2018).

Perkembangan teknologi informasi memberikan pengaruh yang sangat besar pada kehidupan manusia hampir di setiap bidang kehidupan. Contohnya adalah pada bidang pendidikan, yang dengan diterapkannya teknologi informasi terbukti meningkatkan efektivitas dan efisiensi lembaga pendidikan. Salah satu teknologi yang cukup dikenal adalah QR Code (Nugraha, 2011).

QR merupakan singkatan dari Quick Response atau respons cepat, sesuai dengan namanya maka $Q R$ Code dapat menyampaikan informasi dengan cepat dan mendapat respons yang cepat dari alat scanner (Bahtiar, 2012). QR Code merupakan evolusi dari barcode yang awalnya satu dimensi menjadi dua dimensi. $Q R$ Code memiliki kemampuan menyimpan data yang lebih jauh besar daripada barcode (Nugraha, 2011). Barcode atau kode batang hanya mampu menyimpan informasi secara horizontal sedangkan $Q R$ Code mampu menyimpan informasi lebih banyak, baik secara horizontal maupun vertikal (Sholeh, 2016).

Berdasarkan latar belakang yang telah disebutkan, maka dibuatlah sistem informasi akademik berbasis website yang memanfaatkan $Q R$ Code sebagai media absensi. Selain sebagai media absensi, $Q R$ Code juga bisa digunakan untuk login akun masing-masing peserta didik yang terdaftar pada sistem. Selain itu Sistem Informasi Akademik yang dikembangkan juga dilengkapi dengan fitur notifikasi pembayaran otomasis menggunakan API (Application Programming Interface) berupa pesan whatsapp. Whatsapp merupakan aplikasi berkirim pesan yang mempunyai fungsi dasar yang sama dengan SMS (Short Message Service). Tidak hanya pesan teks, whatsapp juga bisa digunakan untuk berkirim pesan gambar, video, audio, dan lain sebagainya.

\subsection{Rumusan Masalah}

Berdasarkan latar belakang yang telah diuraikan, maka rumusan masalah yang dapat diambil adalah sebagai berikut.

a. Bagaimana menerapkan $Q R$ Code sebagai media login pada sistem informasi akademik?

b. Bagaimana menerapkan $Q R$ Code sebagai media absensi pada sistem informasi akademik?

c. Bagaimana cara mengirimkan pesan whatsapp otomatis sebagai media notifikasi pada sistem informasi akademik?

\subsection{Tujuan Penelitian}

Adapun tujuan yang ingin dicapai dari penelitian ini adalah sebagai berikut. a. Menerapkan $Q R$ Code yang berisi tentang informasi login yaitu berupa username dan password yang digunakan untuk login pada sistem.

b. Menerapkan $Q R$ Code yang berisi identitas siswa sebagai media absensi.

c. Membuat sistem notifikasi otomatis pada sistem informasi akademik dengan menggunakan server API whatsapp yang tersedia di internet.

\subsection{Metode penelitian}

Metode yang akan digunakan untuk mengembangkan perangkat lunak yaitu metode SDLC (Software Development Life Cycle) model waterfall dengan tahapan seperti berikut.

a. Analisis Kebutuhan

Mendefinisikan dan mengumpulkan seluruh kebutuhan yang harus dipenuhi oleh sistem yang akan dibuat.

b. Perancangan

Tahap ini adalah tahap perancangan keseluruhan dan penentuan alur berjalannya sistem, agar sistem yang dibuat berjalan sesuai dengan keinginan.

c. Desain

Tahap desain adalah tahap perancangan antarmuka dari sistem yang akan dibuat agar sistem dapat memenuhi persyaratan yang telah ditetapkan. Seperti perancangan halaman antarmuka dan lain-lain.

d. Implementasi

Implementasi adalah tahap pembuatan kode program sesuai desain yang telah dibuat pada tahap sebelumnya.

e. Integrasi

Integrasi adalah tahap penggabungan kode program yang telah dibuat untuk dilakukan pengujian pada tahap selanjutnya.

f. Pengujian

Pengujian dilakukan untuk mengetahui terdapat kesalahan atautidak pada sistem yang telah dibuat dan memastikam keluaran yang dihasilkan sesuai dengan keinginan.

\subsection{Landasan Teori}

\subsubsection{Sistem Informasi}

Tata Sutabri (2012:46) mengemukakan bahwa sistem informasi adalah suatu sistem di dalam suatu organisasi yang mempertemukan kebutuhan pengolahan transaksi harian yang mendukung fungsi operasi organisasi yang bersifat manajerial dengan kegiatan strategi dari suatu organisasi untuk dapat menyediakan kepada pihak luar tertentu dengan laporan-laporan yang diperlukan.

Sistem informasi terdiri dari komponenkomponen yang disebut blok bangunan, yang terdiri dari blok masukan, blok model, blok keluaran, blok teknologi, blok basis data, dan blok kendali. Sebagai suatu sistem, keenam blok tersebut masing-masing 
saling berinteraksi satu dengan yang lain membentuk suatu kesatuan untuk mencapai sasaran (Kristania, 2017).

\subsubsection{Metode Waterfall}

Pengembangan sistem model waterfall adalah salah satu dari beberapa model dari metode SDLC (Software Development Life Cycle).

Menurut Rosa dan Shalahuddin, (2014:26)

SDLC atau Software Development Life Cycle adalah proses proses mengambangkan atau mengubah suatu sistem perangkat lunak dengan menggunakan model-model dan metodologi yang digunakan orang untuk mengembangkan sistem-sistem perangkat lunak sebelumnya (Larasati, 2017).

Menurut Rosa dan Shalahuddin, (2014:28) metode SDLC (Software Development Life Cycle) model air terjun (waterfall) sering juga disebut model sekuensial linier (sequential linear) atau alur hidup klasik (classic life cycle). Model alur terjun menyediakan pendekatan alur hidup perangkat lunak secara sekuensial atau terurut dimulai dari analisa kebutuhan, perancangan dan desain, pengodean, pengujian dan tahap pendukung atau maintenance (Murni, 2018).

\subsubsection{QR Code}

Qiuck Response Code sering disebut $Q R$ Code atau Kode QR adalah semacam simbol dua dimensi yang dikembangkan oleh Denso Wave yang merupakan anak perusahaan dari Toyota sebuah perusahaan Jepang pada tahun 1994. Tujuan dari $Q R$ Code ini adalah untuk menyampaikan informasi secara cepat dan juga mendapat tanggapan secara cepat. $Q R$ Code adalah perkembangan dari barcode atau kode batang yang hanya mampu menyimpan informasi secara horizontal sedangkan $Q R$ Code mampu menyimpan informasi lebih banyak, baik secara horizontal maupun vertikal (Sholeh, 2016). Contoh $Q R$ Code dapat dilihat pada gambar berikut.

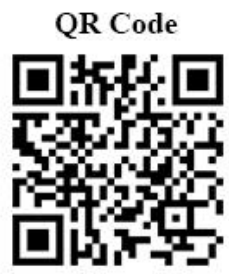

Gambar 1. Contoh Kode QR

$Q R$ Code memiliki beberapa keunggulan dibandingkan dengan jenis-jenis barcode, yaitu:

a. Kapasitas besar

b. Mudah dibaca

c. Kemampuan menyimpan huruf dan angka

d. Dapat dibaca dari berbagai arah

e. Ukuran kecil

f. Tahan terhadap kotor dan rusak

$Q R$ Code terdiri dari pola fungsional untuk memudahkan pembacaan dan area tempat data disimpan. Struktur $Q R$ Code dapat dilihat pada gambar berikut.

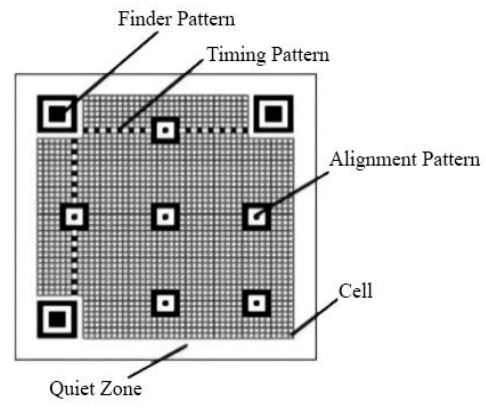

Gambar 2. Struktur Kode QR

Untuk membuat sebuah $Q R$ Code, ada beberapa proses yang harus dilakukan. Karena jenis masukan untuk membuat $Q R$ Code beragam, ada beberapa hal yang harus diperhatikan seperti konversi dari masukan tersebut ke dalam biner sehingga dapat diproses untuk dijadikan titik hitam dan titik putih pada $Q R$ Code yang akan dibuat. Tidak hanya informasi yang telah dikonversi, $Q R$ Code juga harus memiliki pola-pola standar yang dapat memudahkan proses pembacaan (Prathivi, 2019).

\subsubsection{Whatsapp}

Whatsapp adalah aplikasi pesan instan paling populer dibanding layanan pesan instan lain. Fungsi whatsapp hampir sama dengan SMS, tetapi whatsapp tidak menggunakan pulsa, melainkan data internet (Pranajaya, 2018).

Kelebihan whatsapp dibanding aplikasi chatting lain diantaranya yaitu kontak telepon dapat tersinkron otomatis, dapat berbagi foto, gambar, video dan audio dengan penggunaan data yang kecil, dan juga tersedia whatsapp versi web untuk chatting menggunakan perangkat komputer (Karomah, 2018).

\subsubsection{API Whatsapp}

API (Application Programming Interface) whatsapp memungkinkan pengguna untuk mengirim dan menerima pesan whatsapp dalam program mereka sendiri menggunakan soket web atau HTTP. Hal ini dilakukan dengan menggunakan perpustakaan whatsapp-API berbasis PHP untuk mengakses whatsapp. API whatsapp ini dibuat agar pengembang (developer) bisa menggunakan whatsapp-API untuk berinteraksi dengan sistem yang dibangun walaupun proyek mereka tidak ditulis dalam bahasa PHP ataupun menggunakan PHP (Deus, 2018).

\subsection{Kajian Pustaka}

Penelitian yang dilakukan oleh Quratul Aini, Yuliana Isma Graha, dan Siti Ria Zuliana, 2017 dengan judul "Penerapan Absensi QR Code Mahasiswa Bimbingan Belajar Pada Website Berbasis YII Framework". Penelitian tersebut 
menghasilkan aplikasi berbasis website framework yii dengan scan kode QR yang digunakan sebagai media absensi dan penyampai informasi untuk memudahkan pemimpin dan pembimbing mendapatkan rekapitulasi absen. Pada sistem yang dikembangkan dalam penelitian ini, selain untuk absen, kode QR juga dapat digunakan untuk login pada sistem informasi akademik untuk mengecek data identitas pribadi, data pembayaran, nilai raport, dan lain sebagainya. Selain itu sistem juga dilengkapi dengan fitur notifikasi pembayaran otomatis menggunakan pesan whatsapp.

Penelitian yang dilakukan Quratul Aini, Untung Rahardja, dan Anggy Fatillah, 2018 yang berjudul "Penerapan QR Code Sebagai Media Pelayanan Untuk Absensi Pada Website Berbasis PHP Native". Penelitian tersebut menghasilkan sistem absensi dengan memanfaatkan $Q R$ Code yang memudahkan penanggung jawab asisten lab untuk memberikan penilaian absensi terhadap asisten lab dan mencegah terjadinya manipulasi absen. Pada penelitian yang dilakukan, selain mempermudah penangggung jawab untuk merekap absen, $Q R$ Code juga dapat digunakan untuk login pada sistem informasi akademik yang didukung pesan whatsapp sebagai notifikasi pembayaran.

Penelitian yang dilakukan Danindya Puput Muliana Putri, dan Heru Supriono, 2019 yang berjudul "Rancang Bangun Sistem Presensi Berbasis QR Code Menggunakan Framework Codeigniter (Studi Kasus Kehadiran Asisten Praktikum)". Penelitian tersebut menghasilkan sistem presensi berbasis $Q R$ Code yang berbentuk website. Sistem menampilkan rekapitulasi kehadiran dan honor asisten praktikum yang dilengkapi fitur cetak excel dan cetak pdf. Pada penelitian yang dilakukan, sistem yang dikembangkan juga dilengkapi dengan fitur cetak laporan absensi dalam bentuk pdf agar rekapitulasi absen lebih mudah dilakukan. Selain sebagai media absensi, $Q R$ Code juga bisa digunakan untuk login pada sistem informasi akademik yang dilengkapi dengan fitur notifikasi pembayaran otomatis berupa pesan whatsapp.

Penelitian yang dilakukan Sri Murni, dan Raja Sabaruddin, 2018 dengan judul "Pemanfaatan QR Code Dalam Pengembangan Sistem Informasi Kehadiran Siswa Berbasis Web". Penelitian tersebut menghasilkan sebuah sistem yang dapat digunakan sebagai media absensi dengan memanfaatkan kode QR yang dilengkapi rekap bahasan dan laporan absen siswa. Yang membedakan dengan penelitian yang dilakukan, selain sebagai media absensi, kode QR juga dapat digunakan untuk login pada akun masing-masing siswa yang telah terdaftar dalam sistem informasi akademik untuk melakukan pengecekan data identitas pribadi, detail data pembayaran, dan nilai hasil ujian. Selain itu sistem juga dilengkapi fitur notifikasi pembayaran otomatis dalam bentuk pesan whatsapp.
Penelitian yang dilakukan Tri Agusti Farma, Riri Okra, dan Sarwo Derta, 2020 yang berjudul "Pengembangan Aplikasi Pembayaran SPP Dan Didukung Oleh Pesan Wa Sebagai Notifikasi Pembayaran Di SMA INS Kayutanam". Penelitian tersebut menghasilkan sebuah sistem aplikasi pembayaran SPP yang memanfaatkan whatsapp sebagai media notifikasi pembayaran di SMA INS Kayutanam. Pada penelitian ini sistem informasi akademik juga dilengkapi dengan fitur notifikasi pembayaran berupa pesan whatsapp. selain itu sistem juga dapat digunakan untuk mencatat data kehadiran siswa dengan memanfaatkan $Q R$ Code sebagai media absensi.

\section{PEMBAHASAN}

Sistem yang dikembangkan dibuat dengan bahasa pemrograman PHP dan javascript dengan database MySQL untuk identifikasi kode QR. Sedangkan untuk notifikasi pembayaran menggunakan bantuan server API whatsapp yang tersedia di internet yaitu wablas.

Sistem yang dibuat memiliki tiga user yaitu admin, guru, dan siswa dengan hak akses yang berbeda-beda. Admin dapat mengelola dan mengakses seluruh kegiatan dalam sistem meliputi input, pengeditan, penghapusan dan pemeliharaan data. User kedua yaitu guru, guru berperan dalam mengelola nilai siswa dan data absensi pada sistem. Guru juga dapat melihat identitas pribadi atau profil dan data mata pelajaran pada sistem. Dan yang terakhir yaitu siswa, siswa dapat melihat identitas pribadi, detail pembayaran, jadwal pelajaran, dan laporan hasil belajar siswa. Berikut merupakan gambaran kegiatan apa saja yang dapat dilakukan user pada sistem dalam bentuk use case diagram.

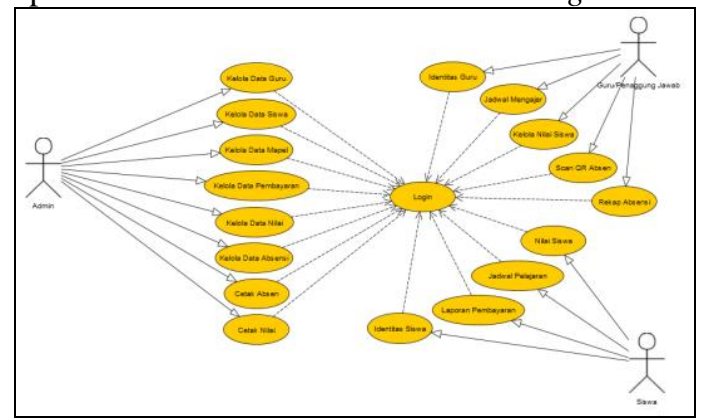

Gambar 3. Use Case diagram

\subsection{Alur Program}

Alur program merupakan rangkaian proses dari sistem yang dikembangkan. Berikut gambaran alur program dari sistem dalam bentuk activity diagram. 


\subsubsection{Alur Login Dengan Kode QR}

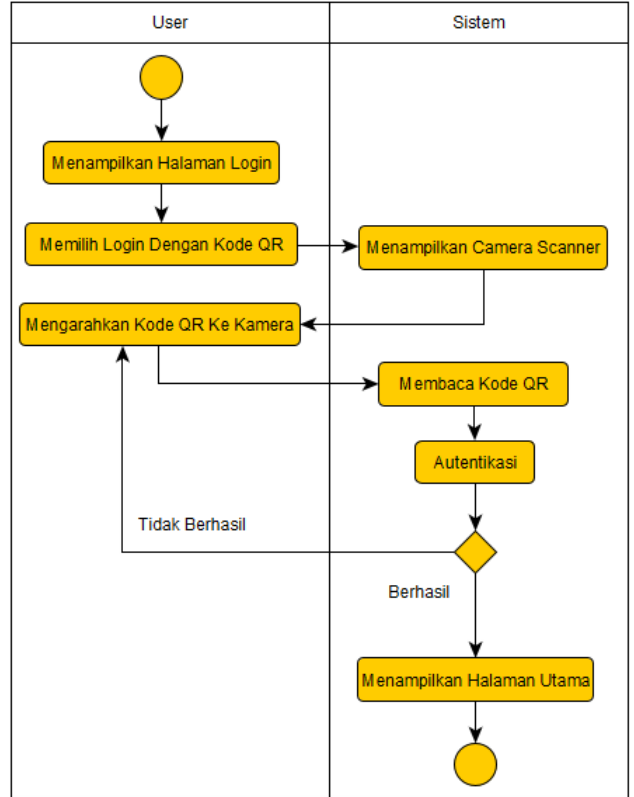

Gambar 4. Alur Login Dengan Kode QR

\subsubsection{Alur Pengiriman Pesan Notifikasi}

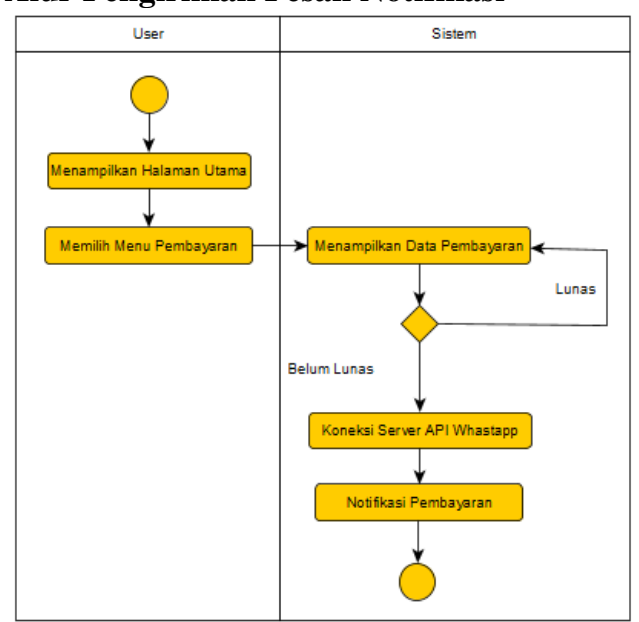

Gambar 5. Alur Pengiriman Pesan Notifikasi
2.1.3 Alur Absensi Dengan Kode QR

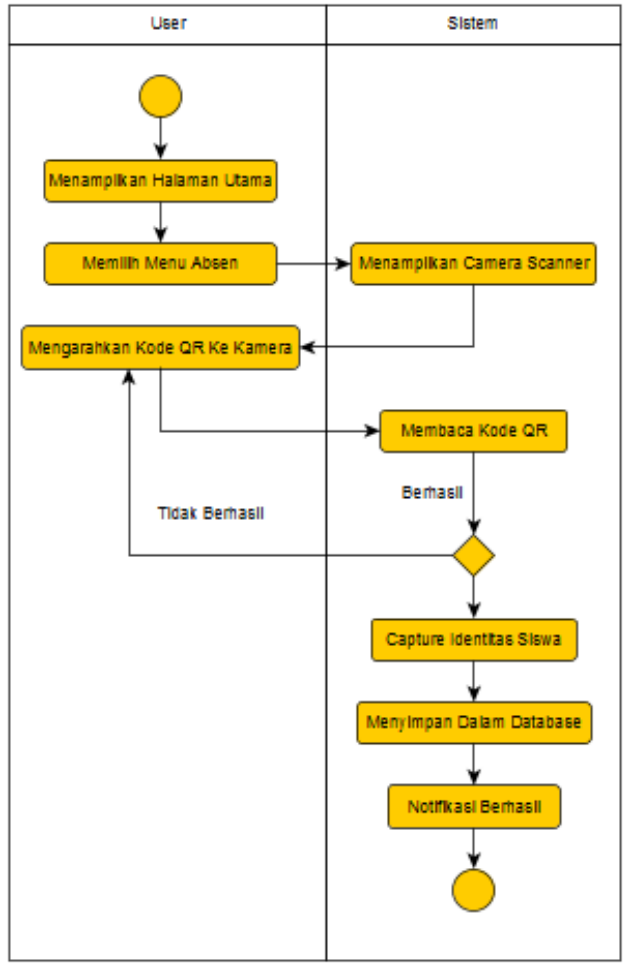

Gambar 6. Alur Absensi Dengan Kode QR

\subsection{Desain Database}

Desain database pada sistem yang dikembangkan digambarkan pada class diagram berikut.

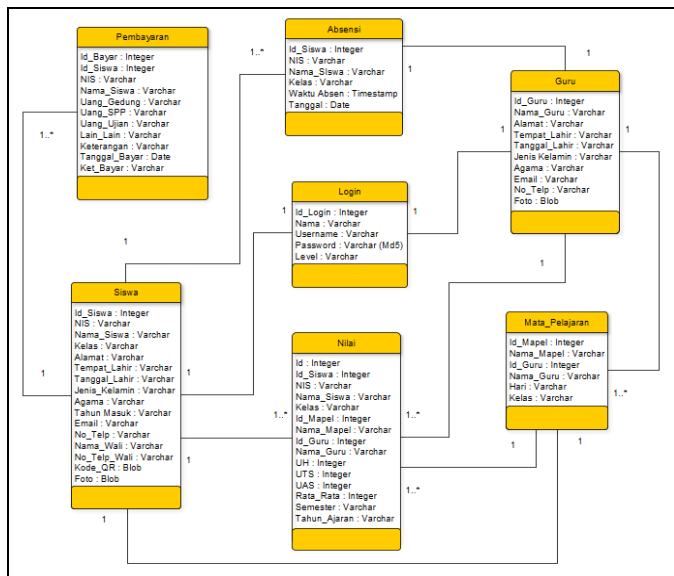

Gambar 7. Class Diagram Desain Database

\subsection{Tampilan Sistem}

2.3.1 Halaman Login

Halaman login adalah halaman utama ketika user mengakses alamat website. Semua user hanya perlu memasukkan username dan password untuk login ke sistem. Selain login dengan cara memasukkan username dan password, siswa juga dapat login dengan cara scan kode QR. 


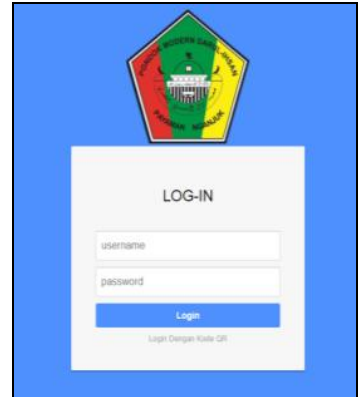

Gambar 8. Tampilan Form Login

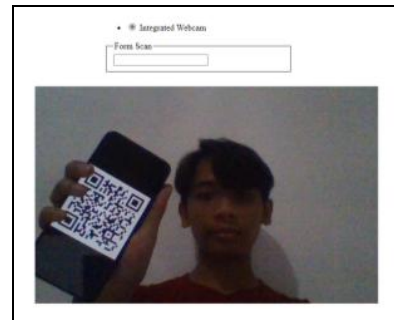

Gambar 9. Tampilan Login Dengan Kode QR

\subsubsection{Halaman Beranda Admin}

Halaman admin mencangkup semua data yang ada pada sistem.

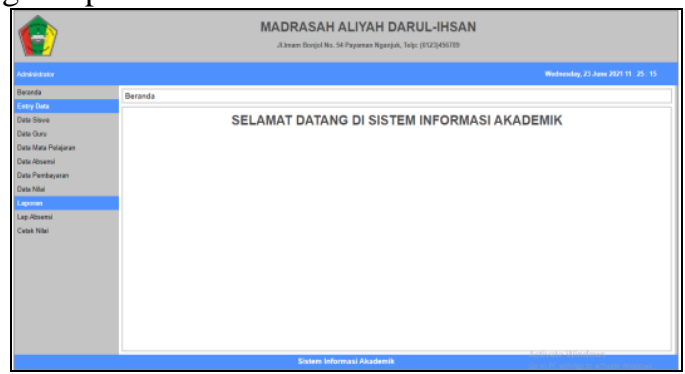

Gambar 10. Halaman Dashboard Admin

\subsubsection{Halaman Beranda Guru}

Menu pada halaman guru mencangkup profil, jadwal, data absensi, input nilai siswa, dan absen.

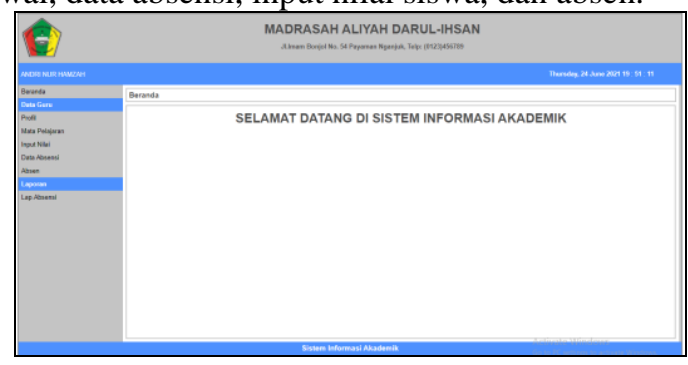

Gambar 11. Halaman Dashboard Guru

\subsubsection{Halaman Absensi}

Halaman absensi siswa dengan memanfaatkan kode QR.

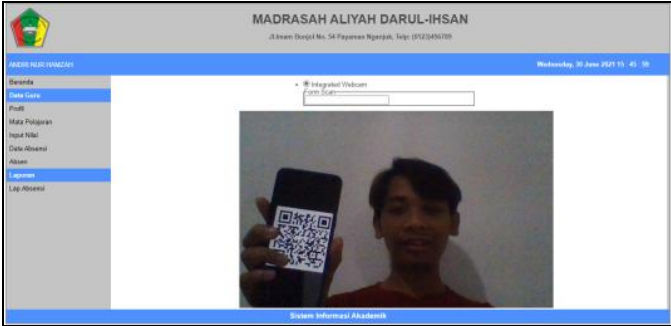

Gambar 12. Tampilan Halaman Absen

\subsubsection{Halaman Beranda Siswa}

Pada halaman siswa terdapat menu profil, pembayaran, jadwal, dan laporan hasil belajar siswa (LHBS).

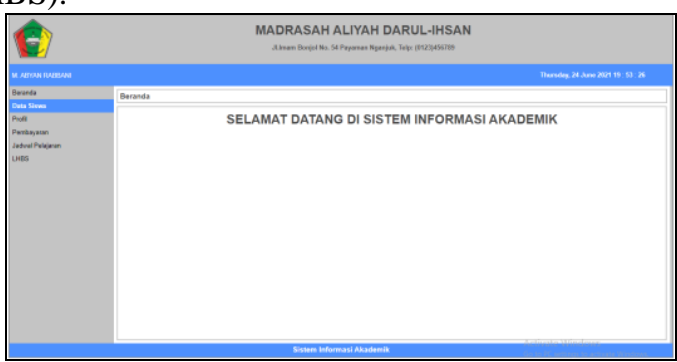

Gambar 13. Halaman Dashboard Siswa

\subsubsection{Halaman Cetak Absen}

Halaman cetak absen hanya dapat diakses oleh admin dan guru. Pada halaman ini admin dan guru dapat mencetak laporan absensi dalam format .pdf sesuai tanggal yang dikehendaki.

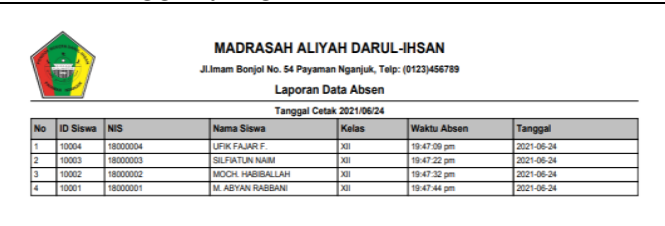

Gambar 14. Halaman Cetak Absen

\subsubsection{Tampilan Notifikasi Pesan Whatsapp}

Notifikasi berupa pesan whatsapp akan didapatkan jika siswa belum melunasi jumlah pembayaran yang telah ditentukan.

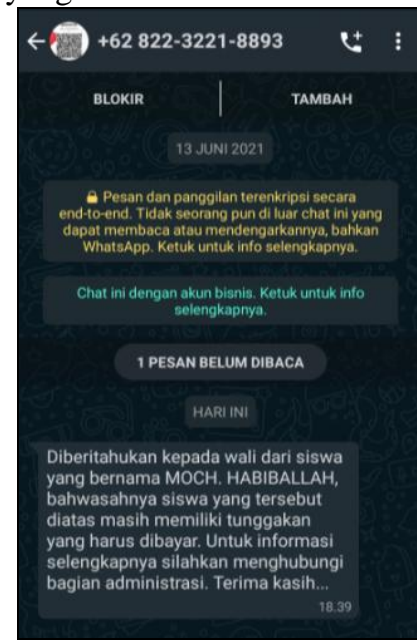

Gambar 15. Tampilan Notifikasi Pembayaran Dengan Pesan Whatsapp 


\subsection{Pengujian}

Bagian ini membahas hasil pengujian dari sistem yang telah dibuat.

2.4.1 Pengujian Sistem Informasi Akademik Tabel 1. Tabel Pengujian Sistem

\begin{tabular}{|c|c|c|c|}
\hline User & Pengujian & Hasil & Kesimpulan \\
\hline \multirow{2}{*}{$\begin{array}{l}\text { Semua } \\
\text { user }\end{array}$} & $\begin{array}{l}\text { Input } \\
\text { username } \\
\text { dan } \\
\text { password } \\
\text { pada } \\
\text { halaman } \\
\text { login }\end{array}$ & $\begin{array}{l}\text { Tampil } \\
\text { beranda } \\
\text { dengan menu } \\
\text { sesuai hak } \\
\text { akses }\end{array}$ & Diterima \\
\hline & Logout & $\begin{array}{l}\text { Kembali ke } \\
\text { halaman } \\
\text { login dengan } \\
\text { notifikasi } \\
\text { berhasil } \\
\text { logout }\end{array}$ & Diterima \\
\hline \multirow{11}{*}{ Admin } & $\begin{array}{l}\text { Klik menu } \\
\text { data siswa }\end{array}$ & $\begin{array}{l}\text { Menampilkan } \\
\text { data siswa }\end{array}$ & Diterima \\
\hline & $\begin{array}{l}\text { Input, edit, } \\
\text { dan hapus } \\
\text { data siswa }\end{array}$ & $\begin{array}{l}\text { Sistem } \\
\text { berjalan } \\
\text { sesuai } \\
\text { perintah }\end{array}$ & Diterima \\
\hline & $\begin{array}{l}\text { Klik opsi } \\
\text { cetak kartu }\end{array}$ & $\begin{array}{l}\text { Cetak kartu } \\
\text { pelajar dalam } \\
\text { format . pdf }\end{array}$ & Diterima \\
\hline & $\begin{array}{l}\text { Klik menu } \\
\text { data guru }\end{array}$ & $\begin{array}{l}\text { Menampilkan } \\
\text { data guru }\end{array}$ & Diterima \\
\hline & $\begin{array}{l}\text { Input, edit, } \\
\text { dan hapus } \\
\text { data guru }\end{array}$ & $\begin{array}{l}\text { Sistem } \\
\text { berjalan } \\
\text { sesuai } \\
\text { perintah }\end{array}$ & Diterima \\
\hline & $\begin{array}{l}\text { Klik menu } \\
\text { data } \\
\text { pembayaran }\end{array}$ & $\begin{array}{l}\text { Menampilkan } \\
\text { data } \\
\text { pembayaran }\end{array}$ & Diterima \\
\hline & & $\begin{array}{l}\text { Siswa yang } \\
\text { belum } \\
\text { melunasi } \\
\text { pembayaran } \\
\text { mendapatkan } \\
\text { notifikasi } \\
\text { berupa pesan } \\
\text { whatsapp }\end{array}$ & $\begin{array}{l}\text { Diterima } \\
\text { (notifikasi } \\
\text { akan } \\
\text { terkirim } \\
\text { lebih cepat } \\
\text { jika kondisi } \\
\text { jaringan } \\
\text { stabil) }\end{array}$ \\
\hline & $\begin{array}{l}\text { Input, edit, } \\
\text { dan hapus } \\
\text { data } \\
\text { pembayaran }\end{array}$ & $\begin{array}{l}\text { Sistem } \\
\text { berjalan } \\
\text { sesuai } \\
\text { perintah }\end{array}$ & Diterima \\
\hline & $\begin{array}{l}\text { Klik menu } \\
\text { data absen }\end{array}$ & $\begin{array}{l}\text { Menampilkan } \\
\text { data absen } \\
\text { sesuai } \\
\text { tanggal }\end{array}$ & Diterima \\
\hline & $\begin{array}{l}\text { Klik menu } \\
\text { data mata } \\
\text { pelajaran }\end{array}$ & $\begin{array}{l}\text { Menampilkan } \\
\text { data mata } \\
\text { pelajaran }\end{array}$ & Diterima \\
\hline & $\begin{array}{l}\text { Klik menu } \\
\text { data nilai }\end{array}$ & $\begin{array}{l}\text { Menampilkan } \\
\text { data nilai }\end{array}$ & Diterima \\
\hline
\end{tabular}

Lanjutan Tabel Pengujian Sistem

\begin{tabular}{|c|c|c|c|}
\hline User & Pengujian & Hasil & Kesimpulan \\
\hline \multirow{3}{*}{ Admin } & $\begin{array}{l}\text { Input, edit, } \\
\text { dan hapus } \\
\text { data nilai }\end{array}$ & $\begin{array}{l}\text { Sistem } \\
\text { berjalan } \\
\text { sesuai } \\
\text { perintah }\end{array}$ & Diterima \\
\hline & $\begin{array}{l}\text { Klik menu } \\
\text { lap. } \\
\text { Absensi }\end{array}$ & $\begin{array}{l}\text { Cetak } \\
\text { laporan } \\
\text { absensi } \\
\text { dalam format } \\
\text {.pdf sesuai } \\
\text { tanggal yang } \\
\text { dikenehdaki }\end{array}$ & Diterima \\
\hline & $\begin{array}{l}\text { Klik menu } \\
\text { cetak nilai }\end{array}$ & $\begin{array}{l}\text { Cetak nilai } \\
\text { dalam format } \\
\text {.pdf sesuai } \\
\text { nama siswa } \\
\text { yang } \\
\text { dikehendaki }\end{array}$ & Diterima \\
\hline \multirow{6}{*}{ Guru } & $\begin{array}{l}\text { Klik menu } \\
\text { profil }\end{array}$ & $\begin{array}{l}\text { Menampilkan } \\
\text { profil guru }\end{array}$ & Diterima \\
\hline & $\begin{array}{l}\text { Klik menu } \\
\text { mata } \\
\text { pelajaran }\end{array}$ & $\begin{array}{l}\text { Menampilkan } \\
\text { data jadwal } \\
\text { pelajaran } \\
\text { masing- } \\
\text { masing guru }\end{array}$ & Diterima \\
\hline & $\begin{array}{l}\text { Klik menu } \\
\text { input nilai }\end{array}$ & $\begin{array}{l}\text { Menampilkan } \\
\text { menu input } \\
\text { nilai siswa }\end{array}$ & Diterima \\
\hline & $\begin{array}{l}\text { Klik menu } \\
\text { data absensi }\end{array}$ & $\begin{array}{l}\text { Menampilkan } \\
\text { data absensi } \\
\text { sesuai } \\
\text { tanggal yang } \\
\text { dikehendaki }\end{array}$ & Diterima \\
\hline & $\begin{array}{l}\text { Klik menu } \\
\text { absen }\end{array}$ & $\begin{array}{l}\text { Menampilkan } \\
\text { kamera } \\
\text { pemindai } \\
\text { untuk absen }\end{array}$ & Diterima \\
\hline & $\begin{array}{l}\text { Klik menu } \\
\text { lap. } \\
\text { Absensi }\end{array}$ & $\begin{array}{l}\text { Cetak } \\
\text { laporan } \\
\text { absensi } \\
\text { dalam format } \\
\text {.pdf sesuai } \\
\text { tanggal yang } \\
\text { dikehendaki }\end{array}$ & Diterima \\
\hline \multirow{4}{*}{ Siswa } & $\begin{array}{l}\text { Klik menu } \\
\text { profil }\end{array}$ & $\begin{array}{l}\text { Menampilkan } \\
\text { profil siswa }\end{array}$ & Diterima \\
\hline & $\begin{array}{l}\text { Klik menu } \\
\text { pembayaran }\end{array}$ & $\begin{array}{l}\text { Menampilkan } \\
\text { data } \\
\text { pembayaran } \\
\text { siswa }\end{array}$ & Diterima \\
\hline & $\begin{array}{l}\text { Klik menu } \\
\text { jadwal } \\
\text { pelajaran }\end{array}$ & $\begin{array}{l}\text { Menampilkan } \\
\text { data jadwal } \\
\text { pelajaran } \\
\text { sesuai kelas }\end{array}$ & Diterima \\
\hline & $\begin{array}{l}\text { Klik menu } \\
\text { LHBS }\end{array}$ & $\begin{array}{l}\text { Menampilkan } \\
\text { data hasil } \\
\text { belajar siswa }\end{array}$ & Diterima \\
\hline
\end{tabular}




\subsubsection{Pengujian Pemindaian Kode QR}

a. Skenario Pertama

Pengujian dilakukan terhadap $Q R$ Code yang dicetak dalam berbagai ukuran dengan pemindaian yang dilakukan dari berbagai jarak.

Tabel 2. Tabel Pengujian Kode QR Pertama

\begin{tabular}{|c|c|c|c|}
\hline No & $\begin{array}{l}\text { Ukuran } \\
\text { Kode } Q R\end{array}$ & Jarak & Hasil \\
\hline \multirow[t]{5}{*}{1} & \multirow{5}{*}{$\begin{array}{l}200 \times 200 \\
\text { pixel }\end{array}$} & $1-7 \mathrm{~cm}$ & Diterima \\
\hline & & $8-14 \mathrm{~cm}$ & Diterima \\
\hline & & $15-21 \mathrm{~cm}$ & Diterima \\
\hline & & $22-28 \mathrm{~cm}$ & Diterima \\
\hline & & $>35 \mathrm{~cm}$ & Diterima \\
\hline \multirow[t]{5}{*}{2} & \multirow{5}{*}{$\begin{array}{l}150 \times 150 \\
\text { pixel }\end{array}$} & $1-7 \mathrm{~cm}$ & Diterima \\
\hline & & $8-14 \mathrm{~cm}$ & Diterima \\
\hline & & $15-21 \mathrm{~cm}$ & Diterima \\
\hline & & $22-28 \mathrm{~cm}$ & Diterima \\
\hline & & $>35 \mathrm{~cm}$ & Ditolak \\
\hline \multirow[t]{5}{*}{3} & \multirow{5}{*}{$\begin{array}{l}100 \times 100 \\
\text { pixel }\end{array}$} & $1-7 \mathrm{~cm}$ & Diterima \\
\hline & & $8-14 \mathrm{~cm}$ & Diterima \\
\hline & & $15-21 \mathrm{~cm}$ & Diterima \\
\hline & & $22-28 \mathrm{~cm}$ & Ditolak \\
\hline & & $>35 \mathrm{~cm}$ & Ditolak \\
\hline \multirow[t]{5}{*}{4} & \multirow{5}{*}{$\begin{array}{l}50 \times 50 \\
\text { pixel }\end{array}$} & $1-7 \mathrm{~cm}$ & Ditolak \\
\hline & & $8-14 \mathrm{~cm}$ & Ditolak \\
\hline & & $15-21 \mathrm{~cm}$ & Ditolak \\
\hline & & $22-28 \mathrm{~cm}$ & Ditolak \\
\hline & & $>35 \mathrm{~cm}$ & Ditolak \\
\hline
\end{tabular}

b. Skenario Kedua

Pengujian dilakukan terhadap $Q R$ Code dalam berbagai keadaan.

Tabel 3. Tabel Pengujian Kode QR Kedua

\begin{tabular}{|l|l|l|}
\hline No & Keadaan Kode QR & Hasil \\
\hline 1 & $\begin{array}{l}\text { Kode QR dalam } \\
\text { keadaan kotor }\end{array}$ & Diterima \\
\hline 2 & $\begin{array}{l}\text { Kode QR dalam } \\
\text { keadaan sobek (tanpa } \\
\text { menghilangkan } \\
\text { anggota gambar Kode } \\
\text { QR) }\end{array}$ & Diterima \\
\hline 3 & $\begin{array}{l}\text { Pemindaian dalam } \\
\text { keadaan lampu ruangan } \\
\text { mati (penerangan } \\
\text { hanya menggunakan } \\
\text { flash pada kamera } \\
\text { webcam) }\end{array}$ & Diterima \\
\hline
\end{tabular}

\section{KESIMPULAN}

Beberapa kesimpulan yang dapat diambil diantaranya adalah sebagai berikut.

a. Sistem dibangun dengan menggunakan bahasa pemrograman PHP dengan database MySQL dalam bentuk aplikasi berbasis website.

b. Pengiriman notifikasi otomatis berupa pesan whatsapp menggunakan API whatsapp yang tersedia di internet yaitu wablas.

c. Pemindaian kode QR menjadi lebih sulit jika ukuran kode QR mengalami penyusutan.

d. Jarak terbaik rata-rata untuk memindai kode QR adalah antara $5-20 \mathrm{~cm}$, tergantung dari ukuran kode $\mathrm{QR}$ yang dipindai.

e. Kondisi cahaya juga memengaruhi pemindaian kode QR.

f. Kode QR tetap terbaca meskipun dalam keadaan sobek dan kotor selama keadaan gambar masih utuh dan pola-pola kode QR tidak tertutup kotoran.

g. Pengiriman notifikasi pesan whatsapp akan lebih cepat jika kecepatan jaringan stabil.

\section{PUSTAKA}

Aini, Q., Graha, Y. I. \& Zuliana, S. R. 2017. Penerapan Absensi QR Code Mahasiswa Bimbingan Belajar Pada Website Berbasis YII Framework. Sisfonetika 7 (2), 207-218.

Aini, Q., Raharja, U. \& Fatillah, A. 2018. Penerapan QR Code Sebagai Media Pelayanan Untuk Absensi Pada Website Berbasis PHP Native. Sisfonetika 8 (1), 47-56

Bahtiar, M. \& Mazharuddin, A. 2012. Smart Login Pada Situs Web Menggunakan QR Code. Jurnal Teknik POMITS 1 (1).

Deus, F. M. 2018. Implementasi Teknologi API Whatsapp Pada Aplikasi Penjadwalan Rawat Jalan Berbasis Web. STMIK AKAKOM YOGYAKARTA.

Farma, T. A., Okra, R. \& Derta, S. 2020. Pengembangan Aplikasi Pembayaran SPP Dan Didukung Oleh Pesan WA Sebagai Notifikasi Pembayaran Di SMA INS Kayutanam. InfoTekJar: Jurnal Nasional Informatika Dan Teknologi Jaringan 5 (1), 132-137.

Iwaman, B. H., Riady, S. R. \& Sofi, K. 2018. Penerapan Absensi Kuliah Berbasis QR Code Dengan Modul Raspberry Pi3 Menggunakan Metode Arsitektur Zachman Framework. Prosiding Seminar Nasional Unimus 1.

Karomah, P. R. 2018. Efektifitas Pemanfaatan Aplikasi Whatsapp Sebagai Sarana Diskusi Pembelajaran Pada Mahasiswa Fakultas Ekonomidan Bisnis Universitas Negeri Jember Angkatan 2015. Universitas Muhammadiyah Jember, 2018.

Kristania, Y. M., Maryani, I. \& Asyifudin, I. 2017. Sistem Informasi Akademik Berbasis Web Pada SMK Negeri 2 Banyumas. Repository Nusamandiri.

Larasati, H. \& Masripah, S. 2017. Analisa Dan Perancangan Sistem Informasi Pembelian GRC Dengan Metode Waterfall. Jurnal Pilar Nusa Mandiri 13 (2), 193-198.

Lengkong, O. H., Fiden, D. H., \& Masrikat, A. 2016. Sistem Informasi Absensi Real-Time Di 
Universitas Klabat. CoglTo Smart Journal 2 (2), 216-228.

Murni, S., \& Sabaruddin, R. 2018. Pemanfaatan QR Code Dalam Pengembangan Sistem Informasi Kehadiran Siswa Berbasis Web. Jurnal Teknologi dan Manajemen Informatika 4 (2).

Nugraha, M. P. \& Munir, R. 2011. Pengembangan Aplikasi QR Code Generator Dan QR Code Reader Dari Data Berbentuk Image. Informatict National Conference, 148-149.

Pranajaya \& Wicaksono, H. 2018. Pemanfaatan Aplikasi Whatssapp (WA) Di Kalangan Pelajar: Studi Kasus Di MTs Al Muddatsiriyah Dan MTs Jakarta Pusat. Orbith: Majalah Ilmiah Pengembangan Rekayasa Dan Sosial 14 (1).

Prathivi, R. 2019. Analisa Sistem QR Code Untuk Identifikasi Buku Perpustakaan. Jurnal Pengembangan Rekayasa dan teknologi 14 (2), 37- 40.

Putri, D. P. M., \& Supriono, H. 2019. Rancang Bangun Sistem Presensi Berbasis QR Code Menggunakan Framework Codeigniter (Studi Kasus Kehadiran Asisten Praktikum). Jurnal INSYPRO (Information System And Processing) 4 (1), 17-26.

Rosa, A. S. \& Salahuddin, M. 2014. Rekayasa Perangkat Lunak. Bandung: Informatika

Setiawan, E., B., \& Kurniawan, B. (2015). Perancangan Sistem Absensi Kehadiran Perkuliahan Dengan Menggunakan Radio Frequency Identification (RFId). Jurnal CoreIT: Jurnal hasil Penelitian Ilmu Komputer dan Teknologi Informasi 1 (2), 44-49.

Sholeh, M. L., \& Muharom, L. A. 2016. Smart Presensi Menggunakan Qr-Code Dengan Enkripsi Vignere Cipher. J. Math. And Its Appl 13 (2).

Sutabri, Tata. 2012. Konsep Sistem Informasi. Jakarta: Andi Offset. 